\title{
Emerging regulatory roles of mitochondrial sirtuins on pyruvate dehydrogenase complex and the related metabolic diseases: Review
}

\author{
Abolfazl Nasiri ${ }^{1,2}$, Masoud Sadeghi ${ }^{3}$, Asad Vaisi-Raygani ${ }^{2,4}$, Sara Kiani ${ }^{3}$, Zahra Aghelan ${ }^{1,2}$, \\ Reza Khodarahmi ${ }^{3,5}$,*
}

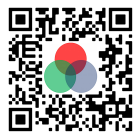

Use your smartphone to scan this QR code and download this article

${ }^{1}$ Students Research Committee, Kermanshah University of Medical Sciences, Kermanshah, Iran

${ }^{2}$ Department of Clinical Biochemistry, School of Medicine, Kermanshah University of Medical Sciences, Kermanshah, Iran

${ }^{3}$ Medical Biology Research Center, Kermanshah University of Medical Sciences, Kermanshah, Iran

${ }^{4}$ Fertility and Infertility Research Center, Health Technology Institute, Kermanshah University of Medical Sciences, Kermanshah, Iran

${ }^{5}$ Department of Pharmacognosy and Biotechnology, Faculty of Pharmacy, Kermanshah University of Medical Sciences, Kermanshah, Iran

\section{Correspondence}

Reza Khodarahmi, Medical Biology Research Center, Kermanshah University of Medical Sciences, Kermanshah, Iran

Department of Pharmacognosy and Biotechnology, Faculty of Pharmacy, Kermanshah University of Medical Sciences, Kermanshah, Iran

Email: rkhodarahmi@mbrc.ac.ir History

- Received: Aug 06, 2019

- Accepted: Dec 23, 2019

- Published: Feb 29, 2019

DOI : 10.15419/bmrat.v7i2.591

\section{Check for updates}

\section{Copyright}

(c) Biomedpress. This is an openaccess article distributed under the terms of the Creative Commons Attribution 4.0 International license.

\begin{abstract}
The pyruvate dehydrogenase complex (PDC) is a multi-enzyme complex of the mitochondria that provides a link between glycolysis and the Krebs cycle. PDC plays an essential role in producing acetyl-CoA from glucose and the regulation of fuel consumption. In general, PDC enzyme is regulated in two different ways, end-product inhibition and posttranslational modifications (more extensive phosphorylation and dephosphorylation subunit E1). Posttranslational modifications of this enzyme are regulated by various factors. Sirtuins are the class III of histone deacylatases that catalyze protein posttranslational modifications, including deacetylation, adenosine diphosphate ribosylation, and deacylation. Sirt3, Sirt4, and Sirt5 are mitochondrial sirtuins that control the posttranslational modifications of mitochondrial protein. Considering the comprehensive role of sirtuins in post-translational modifications and regulation of metabolic processes, the aim of this review is to explore the role of mitochondrial sirtuins in the regulation of the PDC. PDC deficiency is a common metabolic disorder that causes pyruvate to be converted to lactate and alanine rather than to acetyl-CoA. because this enzyme is in the gateway of complete oxidation, glucose products entering the Krebs cycle and resulting in physiological and structural changes in the organs. Metabolic blockage such as ketogenic diet broken up by $\beta$-oxidation and producing acetyl-CoA can improve the patients. Sirtuins play a role in the production of acetyl-CoA through oxidation of fatty acids and other pathways. Thus, we hypothesize that the targets and bioactive compounds targeting mitochondrial sirtuins can be involved in the treatment of PDC deficiency. In general, this review discusses the present knowledge on how mitochondrial sirtuins are involved in the regulation of PDC as well as their possible roles in the treatment of PDC deficiency.
\end{abstract}

Key words: Pyruvate dehydrogenase complex deficiency, Mitochondrial Sirtuins, protein deacetylation

\section{INTRODUCTION}

The human pyruvate dehydrogenase (PD) is a multienzyme complex that is involved in the production of nicotinamide adenine dinucleotide dehydrogenase (NADH), carbon dioxide (CO2), and acetylcoenzyme A (CoA) by pyruvate decarboxylation. The common pyruvate dehydrogenase complex (PDC) has three main enzymes and five coenzymes ${ }^{1-7}$. The three components enzymes PDC include pyruvate dehydrogenase (E1, a heterotetramer of two types, with EC 1.2.4.1), dihydrolipoamide acetyltransferase (E2, EC 2.3.1.12) and dihydrolipoamide dehydrogenase (E3, EC 1.8.1.4, $)^{8,9}$. E3 binding protein (E3BP) is an additional subunit that exists in humans, and integrates stable E3 into the E2 core of each assembly ${ }^{9-11}$. Each assembly consists of five coenzymes, including thiamine pyrophosphat, lipoic acid, CoA, flavin adenine dinucleotide, and nicotinamide adenine dinucleotide $\left(\mathrm{NAD}^{+}\right)$. $\mathrm{PDC}$ and its regulatory enzymes have an important role in all mitochondria of higher eukaryotes. This complex is active in aerobic conditions that require glucose decomposition to produce energy, and is suppressed when glucose is in short supply. In general, this enzyme is regulated in two different ways, end-product inhibition by acetyl CoA and $\mathrm{NADH}^{12}$ and phosphorylation and dephosphorylation subunit $\mathrm{E} 1$, which are a non-phosphorylated active form and a phosphorylated inactive form. However, its regulation is not fully understood. PDC deficiency is a mitochondrial defect, whose gene is encoded in the nucleus and the most identified motive over neonatal encephalopathies with primary lactic acidosis ${ }^{13}$. PDC deficiency may be triggered by the defects of $\mathrm{E} 1 \alpha$, $\mathrm{E} 1 \beta$, E2, or E3 subunits. This deficiency is often due to alteration in the $\mathrm{E} 1$ gene located on $\mathrm{X}$ chromosome; all other causes are due to defects in recessive genes $^{14-16}$. Several strategies have been reported to 
be useful in the treatment of PDC deficiency. These encompass the use of ketogenic diets (KD), administration of dichloroacetate and thiamine supplements. Unfortunately, none of these is generalized ${ }^{14-16}$. Sirtuins are protected enzymes in most species, including humans and bacteria. They rely on $\mathrm{NAD}^{+}$for their reaction (Figure 1). Recently, it has been observed that sirtuins can catalyze reactions including deacetylation, adenosine diphosphate (ADP) ribosylation, and deacylation ${ }^{17}$. The mammalian deacetylases are divided into four classes I, II, III, and IV, based on sequence homology ${ }^{18}$. Classes I, II, and IV mammalian deacetylases include enzymes that contain zinc as a cofactor in their structure. The zinc cofactor plays a role in activating water molecules as a nucleophile and hydrolysis of the acetamide bond in acetate and lysine $\varepsilon$-amino group ${ }^{19}$. Class III mammalian deacetylase proteins, which are called sirtuins, have zinc molecules in their structure; however, the zinc elements are not directly involved in the reaction. Instead, Sirtuins utilize nicotinamide adenine dinucleotide $\left(\mathrm{NAD}^{+}\right)$cosubstrate as a cofactor to produce ADP-ribose as a nucleophile ${ }^{20}$. ADP-ribose remains for ADP-ribosylation of the substrate, alternatively on deacetylation, but this reaction is likely to stay aside response ${ }^{21}$. In mammals, seven sirtuins have been discovered, ranging from Sirt1 to Sirt7. Sirt 1 and Sirt 2 are present both in the nucleus and in the cytoplasm, while Sirt6 and Sirt7 are only seen in the nucleus. Sirt3, Sirt4, and Sirt5 are known as mitochondrial Sirtuins (Figure 2) ${ }^{22}$. Based on phylogenetic conservation of the core domain, sirtuins are categorized into five subclasses (I-IV and U). Subclass I contains Sirt1, Sirt2, and Sirt3 with deacetylase activity. Subclass II sirtuins include Sirt4, which exhibits ADP-ribosyltransferase activity ${ }^{23,24}$. Subclass III sirtuins include Sirt5 that exhibits deacylase activity ${ }^{25}$ and weak deacetylase activity ${ }^{26}$. Subclass IV sirtuins contains Sirt6 and Sirt7 that have deacetylase and ADP ribosyltransferase activity ${ }^{27}$. Subclass U sirtuins are exhibited in archaea and bacteria and are intermediate between classes I and IV ${ }^{28}$.

Among the three sirtuins present in the mitochondria matrix (Sirt3, Sirt4, and Sirt5), Sirt3 is the major mitochondrial deacetylase and performs an important control for energy metabolism ${ }^{29,30}$. On the other hand, Sirt4 is a regulator fuel used in the mitochondria $^{31,32}$. However, the role of Sirt 4 in the regulation of mitochondrial metabolic pathways is unknown. Sirt5 is another type of mitochondrial sirtuins that has a role in demalonylase and desuccinylase activities in mammals. These sirtuins play an important role in metabolic, physiological, and biological processes, generally through posttranslational modifications ${ }^{33,34}$. Posttranslational modifications are involved in the regulation of PDC, but their regulation is not well-defined. Considering the comprehensive role of sirtuins in post-translational modifications and the regulation of metabolic processes, this review was conducted to determine whether sirtuins are involved in the regulation of PDC or not. Deficiency of PDC causes pyruvate to be converted into lactate and alanine instead of acetyl-CoA because this enzyme is in the gateway of complete oxidation of glucose products entering the Krebs cycle. Metabolic blockage such as ketogenic diet is broken up by $\beta$ oxidation, and production of acetyl-CoA can improve the condition. The therapies used for the treatment of this deficiency have not been fully successful. Sirtuins are involved in the production of acetyl-CoA through oxidation of fatty acids and other pathway complexes. Thus, pharmacological targets and bioactive compounds targeting mitochondrial sirtuins can be involved in the treatment of PDC deficiency. This review discusses the present knowledge on how mitochondrial sirtuins is involved in the regulation of PDC as well as their possible roles in the treatment of PDC deficiency.

\section{PDC AND ITS REGULATORY FACTORS}

PDC catalyzes the oxidative decarboxylation reaction of pyruvate to acetyl-CoA. The function of this enzyme is irreversible and has a regulatory role in the entry of glucose products into mitochondria. This enzyme interlinks glycolysis to the Krebs cycle, and subsequently to the respiratory chain, therefore, it can be an important for the synthesis of adenosine triphosphate (ATP) by the transfer of electrons (NADH, FADH) to the respiratory chain ${ }^{35}$. In lipogenic tissues, PDC can produce fatty acids and cholesterol through the production of acetyl-CoA. PDC plays an important role in the choice of fuel and summarized metabolic regulation, which is called the "glucosefatty acid cycle" ${ }^{36}$. This term shows the relationship between the use of glucose or fatty acid in muscle cells. The PDC of each assembly includes three component enzymes termed pyruvate dehydrogenase (PD) (E1), dihydrolipoamide acetyltransferase (E2), and dihydrolipoamide dehydrogenase (E3) ${ }^{8,9}$. Human PDC also has an additional subunit called E3BP that integrates stable E3 into the E2 core of each assembly $^{9-11}$. PDC-E1 plays a role in the oxidative decarboxylation of pyruvate and subsequently causes the production and transfer coenzyme $\mathrm{A}$ in the form of 
1- DEACETYLASE

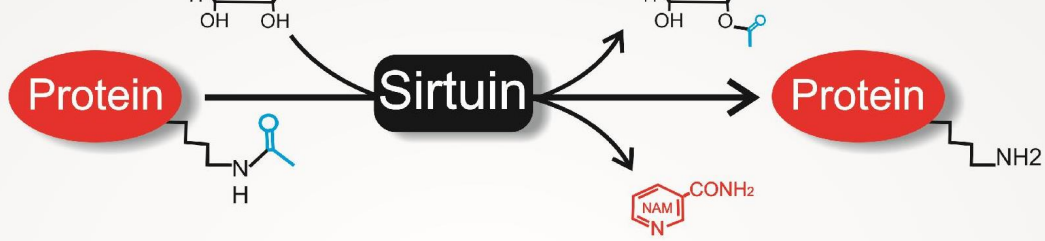

2- MONO-ADP-RIBOSYL TRANSFERASE

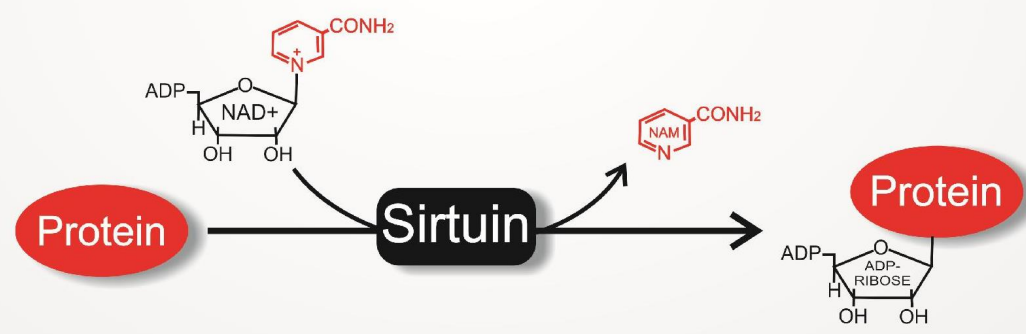

Figure 1: $\mathrm{NAD}^{+}$-dependent deacetylation and ADP ribosyl-transferase of sirtuins. The sirtuins rely on nicotinamide adenine dinucleotide $\left(\mathrm{NAD}^{+}\right)$for their reaction. In the deacetylation process, sirtuins remove the acetate group from the terminal amine of the lysine roots in the structure of a protein and add it to $\mathrm{NAD}^{+}$and releases NAM,2-OAADPr and the deacetylated protein. In the mono-ADP-ribosyl transferase process, the ADP ribosyl root from the NAD ${ }^{+}$added to the protein and releases NAM and ADP-ribosyl protein. Abbreviations: NAM: nicotinamide, 2-OAADPr: 2-O-acetyl-ADP-ribose.

acetyl-CoA to cellular metabolism. To do this, PDCE1 needs thiamine ${ }^{37,38}$. PDC-E2 is another component that plays an essential role in the compartment and function of this multi-enzyme complex ${ }^{39}$, which needs lipoamide in its function. PDC-E3 is involved in electron transfer reactions between flavin adenine dinucleotide $\left(\mathrm{FAD}^{+}\right)$and $\mathrm{NAD}^{+}$(Figure 3 ). There are several copies of these three catalytic enzymes in the PDC. In addition to these enzymes, there are two other enzymes called pyruvate dehydrogenase kinase (PDK, EC 2.7.1.99) and pyruvate dehydrogenase phosphatase (PDP, EC 3.1.3.43) that interact with $\mathrm{PDC}$ complex and have a regulatory role (Figure 4) ${ }^{9-11}$. In general, this enzyme is regulated in two different ways including end-product inhibition by acetyl CoA and $\mathrm{NADH}^{12}$, and phosphorylation and dephosphorylation subunit E1, which are the non-phosphorylated active form and phosphorylated inactive form ${ }^{40}$. Nevertheless, PDC is mostly regulated by kinase and phosphatase ${ }^{41}$, both of which, the control mechanisms often depend on the same metabolic effectors ${ }^{42}$. More substantial physiologi- cal roles occur via phosphorylation and dephosphorylation of three serine residues located on the $\alpha$ subunit (E1) catalyzed by PDK and PDP. In mammalian tissues, there are four isoenzymes for PDKs and two isoenzymes for $\mathrm{PDP}^{43}$. The basis of pyruvate kinase is apparently unrelated tyrosine kinases and serine-threonine kinases in other mammalian regulatory processes ${ }^{43,44}$. Although PDK is associated with the kinase family, the regulation of PDC activity by PDK results from diverse allosteric modulators. To increase the $\mathrm{NADH}$ ratio to $\mathrm{NAD}^{+}$, and acetyl-CoA to $\mathrm{CoASH}$, increases the activity of allosteric pyruvate kinase, and results in the inhibition of PDC activity in response to a lack of mitochondrial demand ${ }^{3,4,6,45-47}$. Elevated pyruvate and ADP levels inhibit the activity of PDK (activating PDC). In general, PDC is activated through its substrates, $\mathrm{CoA}-\mathrm{SH}$ and $\mathrm{NAD}^{+}$, and kinase inhibition, and is inhibited by its products, acetyl $\mathrm{CoA}$ and $\mathrm{NADH}$, and activation of the kinase. In addition, $\mathrm{Mg}^{2+}$ and $\mathrm{Ca}^{2+}$ regulate the catalytic activity of PDP, which increases the activity of this enzyme 10 times in the presence of calcium. PDP is inactivated in 


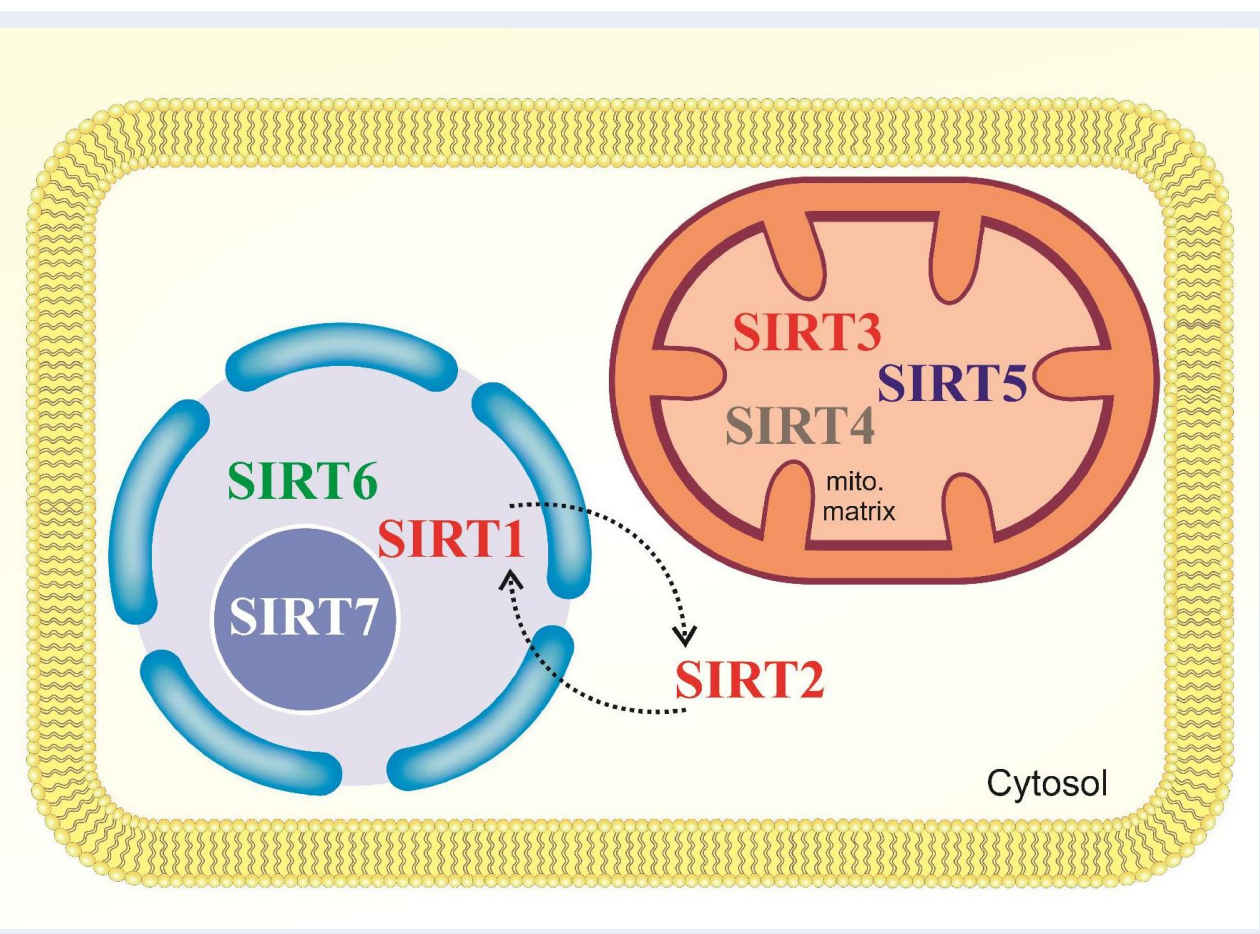

Figure 2: Subcellular localization of the mammalian sirtuins. Sirt1, Sirt2, Sirt6, and Sirt7 are in the nucleus, Sirt1 and Sirt2 are in the cytoplasm, and Sirt3, Sirt4 and Sirt5 are in the mitochondria.

the absence of $\mathrm{Ca}^{2+}$ and $\mathrm{Mg}^{2+6-33,36-46,48}$. The enzymatic activity of PDP relies on the tissue type and the mitochondrial matrix concentrations of $\mathrm{Ca}^{2+}, \mathrm{Mg}^{2+}$, $\mathrm{NADH}$, and insulin ${ }^{49}$.

\section{PDC DEFICIENCY}

Mutation in the gene of PDC enzyme is well-known. PDC deficiency occurs due to mutations in the coding genes of $\mathrm{E} 1 \alpha, \mathrm{E} 1 \beta, \mathrm{E} 2$, or $\mathrm{E} 3$ subunits. The mutation in the pyruvate dehydrogenase E1 (PDH)A1 gene, which encodes the alpha subunit of E1, is the most common mutation ${ }^{50}$, but this mutation is rare in the genes encoding subunits E1 $\beta$ (PDHB $)^{51}$, E2 (DLAT) ${ }^{51}, \mathrm{E} 3$ (DLD) ${ }^{52}$, and E3-binding protein $(\mathrm{PDHX})^{53}$. The mutation in the gene encoding the subunit E1 is located on X chromosome and the defect observed in other genes of the subunits is recessive ${ }^{14-16}$. The mutation in the $\mathrm{X}$ chromosome is $\mathrm{X}$ linked dominant when both females and males have the same defect in the E1 gene. In 25\% children with PDHE1 $\alpha$ deficiency, their mothers carry this mutation. In the rest of most cases, the deficiency of PD is due to new mutations in the $\mathrm{E} 1 \alpha$, and in general, its recurrence is low within any one of the same family ${ }^{54}$. The PDHB, which encodes the E1 $\beta$ subunit of PDC, contains a small amount of PDC deficiency. Although the severity of the symptoms observed in PDHB is similar to that of the PDHA1, it presents considerable phenotypic variability and severity. Defects in other sub-types such as PDP are rare and lead to acidosis in the neonatal period ${ }^{51,55}$.

Sperl et al. ${ }^{56}$ showed that $75.5 \%$ of deficiency of PD in their patients included the mutations in PDHE$1 \alpha$, which showed the same symptoms, and another $13.5 \%$ was due to deficiency of thiamin cofactor. Therefore, an important reason of PDC deficiency is $\mathrm{X}$-linked. More than 120 different mutations have been detected in the E1 $\alpha$ subunit of PDC ${ }^{51,57-59}$. PDC deficiency resulted from E3 deficiency is due to a defect in several $\alpha$-ketoacid dehydrogenases. In general, the activity of PDC is low in these individuals, which shows early clinical onset, and usually, these people die during childhood. Because PDC deficiency causes pyruvate to be converted into lactate and alanine rather than to acetyl-CoA, this enzyme is in the gateway of complete oxidation of glucose products before entering the Krebs cycle. The conversion of glucose into lactate reduces the oxidation of glucose and reduces the amount of ATP generated by the cyclic electron transport and respiratory chain. PDC deficiency causes aggravated hyperpyruvicaemia, lactic acidaemia, and hyperalaninemia ${ }^{60}$. 


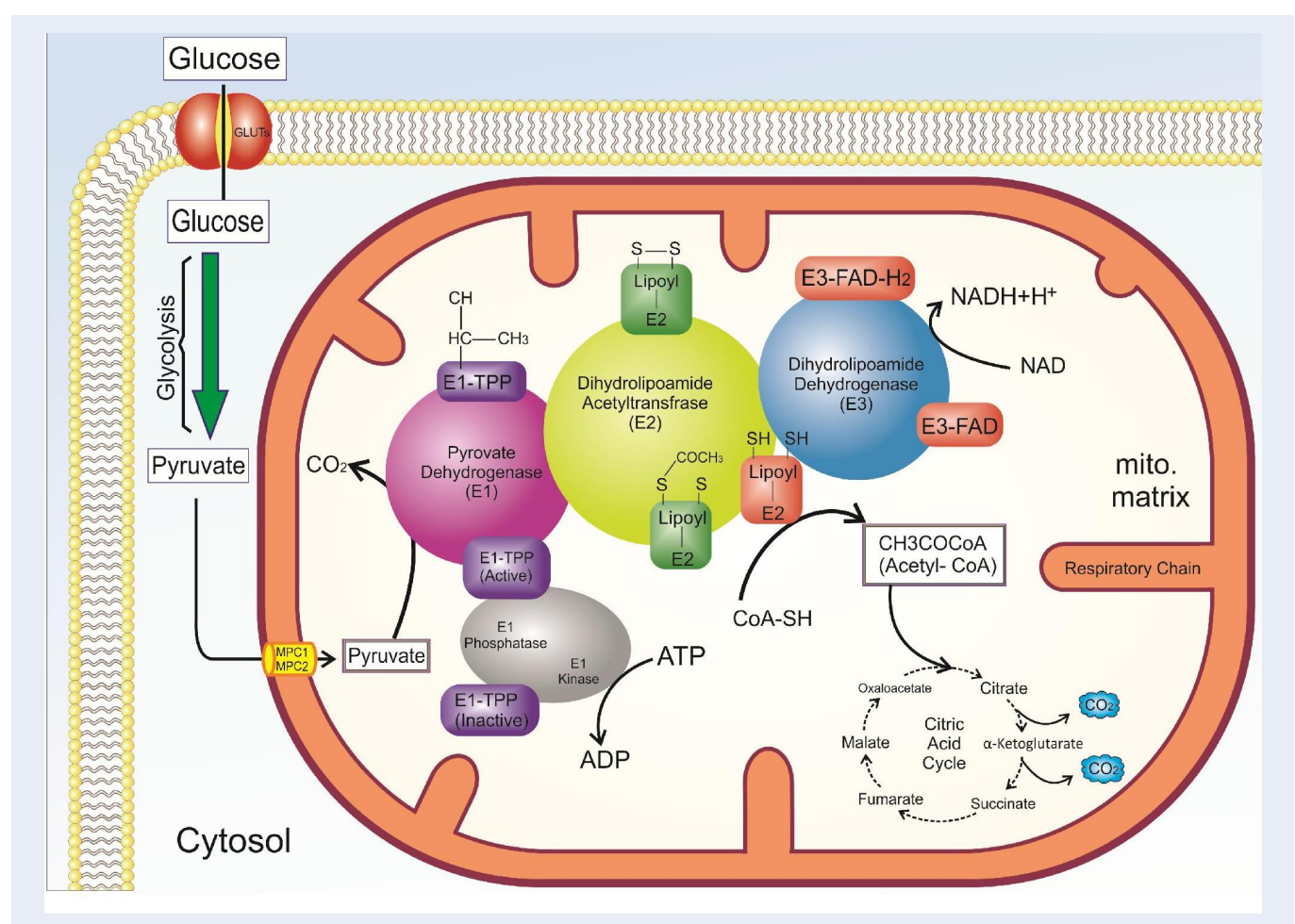

Figure 3: The overall reaction mechanism of the pyruvate dehydrogenase complex (PDC) ${ }^{115}$. The PDC of each assembly includes three component enzymes termed pyruvate dehydrogenase (E1), dihydrolipoamide acetyltransferase (E2), dihydrolipoamide dehydrogenase (E3). This enzyme catalyzes the oxidative decarboxylation reaction of pyruvate to acetyl-CoA. PDC interlinks glycolysis to the Krebs cycle.

\section{CLINICAL SIGNS OF CONGENITAL PDC DEFICIENCY}

The mutation in the PDHA1 gene, which encodes the alpha subunit of E1, is the most common mutation ${ }^{50}$. Symptoms that are commonly seen in PDHE $1 \alpha$ deficiency include delayed growth, hypotonia, ataxia, and seizures. In hemizygous males, the three main symptoms are lactic acidosis during neonatal, Leigh's encephalopathy (the most important respiratory distress or episodic weakness), and periodic ataxia. Clinical symptoms in females with PDHE1 $\alpha$ deficiency are usually uniform although the severity of the incidence depends on variable lyonization ${ }^{61}$. These symptoms include microcephaly, severe to moderate mental retardation, dysmorphic features, and spastic di- or quadriplegia. Deficiency of PDHE1 $\beta$ has been reported in a few cases ${ }^{57,62-64}$. The cause of this deficiency is an increase in proteasome-mediated degradation, and a role of this proteasome is destroying ubiquitinated E1 $\beta$ subunits ${ }^{62}$. Symptoms that are commonly seen in PDHE1 $\alpha$ deficiency include lactic acidosis (early-onset), severely delayed growth with slowly progressive neurological features of the brain stem, basal ganglia, and Leigh syndrome ${ }^{34}$. The most common features of E3BP deficiency (formerly protein $\mathrm{X}$ ) are delayed psychomotor progress, hypotonia, and long-term survival ${ }^{56,65-67}$. Neonatal lactic acidosis slowly progresses with thin corpus callosum and subependymal cysts. Seven cases of E1-phosphatase deficiency were found with hypotonia, feeding trouble, delayed psychomotor progress, and a lethal phenotype in infantile. Mutations in the PDK isoenzyme 3 (PDK3) gene have been found in Charcot-MarieTooth disease type 6. PDK3 mutates through hyperphosphorylation of the PDC, leading to peripheral neuropathy ${ }^{68,69}$.

The genetic defect in the PDC further causes a defect in the nervous system. However, it can lead to abnormality in the function of other tissues such as muscle and liver. In the brain and other tissues, glucose normally generates ATP after oxidation in the glycolysis and TCA cycle. Consequently, PDC deficiency reduces the amount of ATP in the brain and other organs. In addition to the decreased ATP in the brain, the amount of neurotransmitter acetylcholine production decreases and causes the symptoms to be 


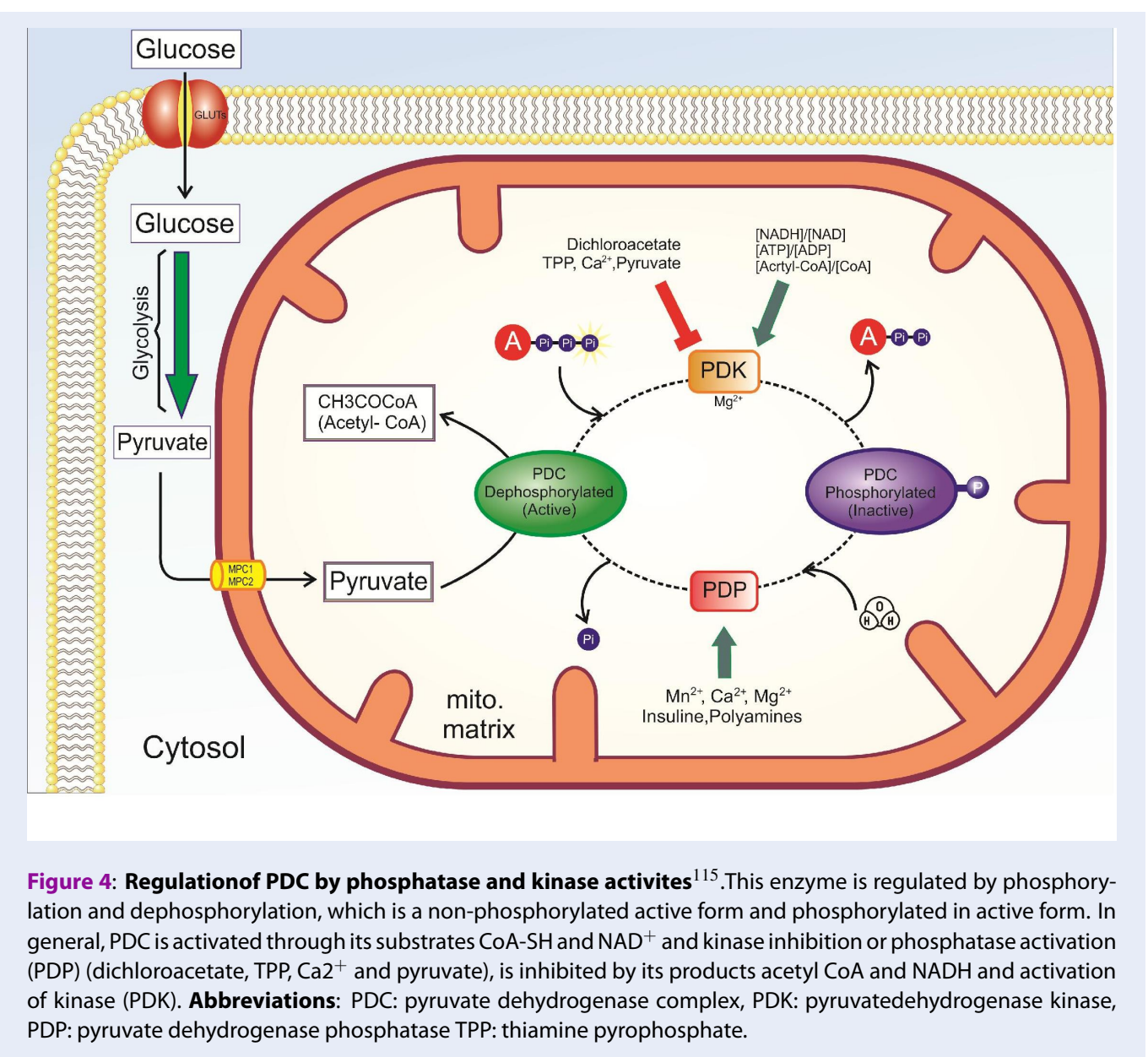

observed in the disease ${ }^{70}$. The history and Biochemical concomitants of congenital PDC deficiency, such as mental retardation, peripheral neuropathy, hypotonia, ataxia, and exercise intolerance in children, are significantly similar to the disease observed during aging $^{71}$. No proven cure exists for the congenital deficiency of PDC and most patients die in the first two decades of life.

\section{MITOCHONDRIAL SIRTUINS}

Sirt3, Sirt4, and Sirt5 with targeting sequences in their N-terminal, which are found in the mitochondrial matrix, are known as mitochondrial sirtuins. Among the three sirtuins present in the mitochondria matrix, Sirt3 is the major mitochondrial deacetylase, which perform an important control for energy metabolism ${ }^{29}$. For this reason, Sirt3 is highly expressed in many active tissues, such as heart, brain, kidney, liver, brown adipose tissue and muscle ${ }^{72}$. Sirt3 is initially synthesized as an inactive enzyme protein and enters the mitochondrial matrix because of the targeting sequence in N-terminal. After the translocation of this protein, the mitochondrial matrix cleavage in the mitochondria by peptidase ${ }^{73}$, which results in the processed 142 amino acids from the $\mathrm{N}$ terminal and subsequently activates it ${ }^{74,75}$.

Sirt4, which is localized in the mitochondria, is a regulator fuel used in the mitochondria ${ }^{31,32}$ and is highly expressed in tissues such as pancreatic beta cells, liver, heart, brain, and kidney ${ }^{22,24,32}$. Sirt4 have mono ADP ribosyltransferase and lipoamidase activity (Figure 5$)^{32}$. Sirt 4 is involved in regulating energy consumption and metabolic processes in the mitochondria $^{31,32}$. However, its complete mechanism is unknown.

Sirt5 is another type of mitochondrial sirtuins that plays a role in demalonylase and desuccinylase activities in mammals (Figure 6 ) $^{76}$. Sirt5 has shown poor deacetylase activity and it lacks ADP ribosyltransferase activity ${ }^{77}$. Sirt5 is able to remove acyl modifications such as succinylation, acetylation, and malonylation on lysine residues. Therefore, Sirt5 appears to be a deacylase rather than a deacetylase ${ }^{25}$. 


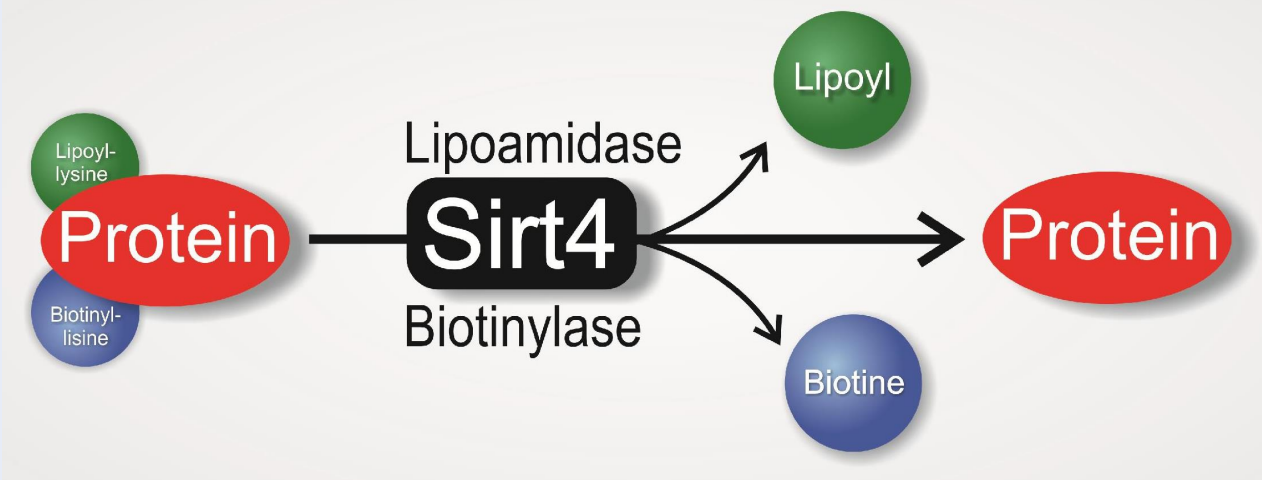

Figure 5: Lipoamidase and biotinylase activity of Sirt4. Sirt4 results in the hydrolysis of lipoyl and biotin groups of protein.

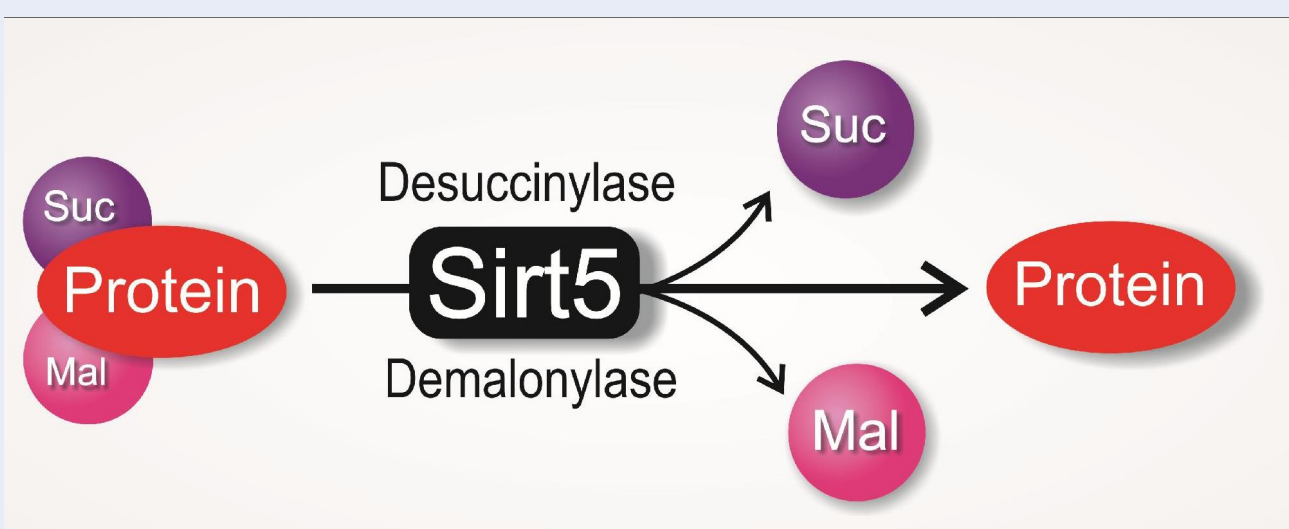

Figure 6: Demalonylase and Desuccinylase activity of Sirt5. Sirt5 results in the hydrolysis of Succinate and malonyl groups of protein.

\section{MITOCHONDRIAL SIRTUINS AND THEIR REGULATORY ROLE IN PDC DEFICIENCY}

Protein posttranslational modifications (PTMs) are indicators of key regulation of cellular processes and proteome diversity. Recently, high-resolution mass spectrometry (MS) has a great contribution to understand an array of modern PTM. In particular, Lys residues are the targets of numerous PTM. Lys groups can fall under acetylation, methylation, biotinylation, ubiquitination $^{76,78,79}$, and other ubiquitination processes like butyrylation, crotonylation, propionylation, succinylation and malonylation ${ }^{76,78-81}$. PDC is known to be regulated through phosphorylation and dephosphorylation by specific PDK and PDP ${ }^{82}$.
PDK1 inactivates PDC by phosphorylation of serine residues, especially in the S293, S300, and S232 positions of PDHA1, whereas PDP1 activates PDC through PDHA1 dephosphorylation. Phosphorylation of the E1 subunit can affect its E1 acetylation $^{83-86}$. Previous studies have reported that Lys acetylation in PDHA1 and PDP1 happens in various cancer cells and epidermal growth factor (EGF) stimulated cells. K321 acetylation of PDHA1 causes the employment of PDK1 to PDHA1, thereby improving PDHA1 phosphorylation. PDHA1 phosphorylation will inhibit it. On the other hand, the PDP1 acetylation inhibits the PDP1, and thereby, dissociates its substrate PDHA1. As a result, it will not be able to dephosphorylate and activate PDHA1. Both of these factors play important roles in promoting 
or inhibiting glycolysis in cancerous cells and tumor growth. Studies have shown that mitochondrial Sirt3 and acetyl-CoA acetyltransferase 1 (ACAT1) regulate deacetylase and acetyltransferase. ACAT1 causes Lys acetylation, and consequently, inhibits PDHA1 and PDP (In general, inhibition of PDC). However, Sirt3 activates Lys deacetylase, and consequently, PDHA1 and PDP1 (In general, activation of PDC). Since the cancer cells are dependent on glycolysis, these metabolic changes are important to them. Therefore, ACAT1 and SIRT3 regulate PDHA1 and PDP1 in the mitochondria through acetylation and deacetylation ${ }^{84,87}$.

The transcription factor of hypoxia inhibitory factor 1$\alpha$ (HIF $1-\alpha)$ is involved in the transcription of numerous genes involved in encoding glycolysis enzymes, including metabolism and glucose transporters. It has been shown that HIF1- $\alpha$ reduces PDC and oxidative phosphorylation (OXPHOS) activity through transactivation of PDKs ${ }^{88}$. Overexpression of HIF1- $\alpha$ occurs in tissues with defective PDC. The production of oxidative stress by complex III leads to increased expression of HIF1- $\alpha$ in PDC deficiency ${ }^{89}$. Sirt3 leads to inhibition of HIF- $1 \alpha$ activity by decreasing ROS production ${ }^{90}$. Sirt3 reduces the production of ROS in mitochondria and cytoplasm through deacetylation of complex III of ETC ${ }^{91}$ and inhibits HIF- $1 \alpha$ activity. Inhibition of HIF- $1 \alpha$ activity leads to reduced transactivation of PDKs, and as a result, increases PDC activity. Therefore, Sirt3 leads to an increase in PDC activity by inhibition of HIF- $1 \alpha$ and transactivation of PDKs.

The lipoamide cofactors are bound to E2 transferase enzymes (Figure 2) and are required for PD activity $^{92}$, forming PD catalytic core. The activity of deacetylase Sirt 4 is low and most of its role is through lipoyl and biotinyllysine modifications. Conversely, Sirt3, Sirt4 regulate the PDC via the hydrolysis of the lipoamide cofactors in the E2 component. Sirt4 decreases the PDC activity by lipoamidase activity, which subsequently generates acetyl-CoA in human cell lines and mouse models ${ }^{87}$.

One of the post-translational modifications is succinylation of proteins. Succinylation occurs on Lys residues and its origin succinyl-CoA ${ }^{93}$. Succinylation can decrease or increase the activity of enzymes. For example, succinylation of PDC and succinate dehydrogenase complexes increases the complex activity ${ }^{94}$. Conversely, succinylation of 3-hydroxy-3methylglutaryl-CoA synthetase 2 (HMGCS2) reduces the activity of the enzymes ${ }^{95}$. Sirt5 is another type of mitochondrial sirtuin that is capable to move desuccinylated Lys residues in proteins ${ }^{96}$. As a result, Sirt5 reduces the activity of PDC through desuccinylase activity.

Consequently, Sirt3 increases the activity of PDC through deacetylation of PDHA1 and PDP1, while Sirt4 decreases the PDC activity through lipoamidase activity and Sirt5 through desuccinylase activity.

\section{METABOLIC AND PHARMACOLOGIC MANAGEMENT OF PDC}

In general, people with PDC deficiency are not very recognizable and their treatment is not adequately effective. Because PDC deficiency causes pyruvate to be converted to lactate and alanine rather than to acetylCoA, this enzyme is in the gateway of complete oxidation glucose products entering the Krebs cycle. The conversion of glucose to lactate reduces the oxidation of glucose and reduces the amount of ATP generated by the cyclic cycle and respiratory chain. PDC deficiency causes aggravated hyperpyruvicaemia, lactic acidaemia, and hyperalaninemia ${ }^{60}$. Several strategies have been reported to be useful in the treatment of PDC deficiency, which encompass the use of ketogenic diet, administration of dichloroacetate, and thiamine supplements ${ }^{97}$. However, none of these strategies are generalized, and they have been reported with variable success.

\section{METABOLIC MANAGEMENT OF DICHLOROACETATE IN PDC DEFICIENCY AND HYPOTHESES RELATED TO THE ROLE OF SIRTUINS IN THIS DISEASE}

PDC is regulated through phosphorylation and dephosphorylation by specific $\mathrm{PDK}$ and $\mathrm{PDP}^{82}$. PDK1 inactivates PDC by phosphorylation of serine residues, especially in S293, S300, and S232 positions of PDHA1, whereas PDP1 activates PDC through PDHA1 dephosphorylation ${ }^{87}$. The regulation of PDC activity by PDKs and PDPs results from diverse allosteric modulators. One of these allosteric modulators is pyruvate, which inhibits the activity of PDKs. Many drugs inhibit all PDK isoforms except PDK3 (testes-specific PDK3) and result in changes in the phosphorylation of the E1 subunits in PDC.

Due to the structural similarity (structural analog) between dichloroacetate (DCA) and pyruvate, DCA can be thought to: 1) Inhibit E1 kinase, and consequently PDC phosphorylation ${ }^{98}, 2$ ) Increase the transferring of pyruvate into mitochondria, and 3) Reduce lactate levels in the serum ${ }^{99}$, leading to increased activity of PDC. DCA is used primarily for the treatment of lactic acidemia in PDC deficiency or respiratory chain 
defects ${ }^{63,68}$. It has been observed that the combination of phenylbutyrate with DCA results in increased activity of PDC in mice ${ }^{100}$. Studies have shown that phenylbutyrate in the fibroblasts of patients with PDC deficiency can also increase the PDC activity ${ }^{101}$.

Sirt3 causes dephosphorylation of PDC by deacetylation PDHA1 and PDP1, and thus, activating PDC (Lys acetylation is inhibiting PDHA1 and PDP1). On the other hand, Sirt3 decreases PDK activity by reducing HIF- $1 \alpha$ and leads to activation of PDC. Therefore, Sirt3 functions similarly to DCA through these two mechanisms.

Short-term consumption of DCA is beneficial for patients with PDC deficiency ${ }^{102}$. However, long-term treatment with DCA causes reversible peripheral neuropathy. For this reason, DCA treatment has remained controversial. Perhaps giving the compounds that activate Sirt3 does not have this harm.

\section{METABOLIC MANAGEMENT OF KD IN PDC DEFICIENCY AND HYPOTHESES RELATED TO THE ROLE OF SIRTUINS IN THIS DISEASE}

Most probably, the best way to treat patients with PDC deficiency is the use of ketogenic supplements ${ }^{103}$. Consumption of KD provides the longchain saturated triglycerides. Providing high-fat foods, instead of glucose-rich foods, reduces glycolysis and increases the production of acetyl-CoA through the beta-oxidation pathway. The increased production of acetyl-CoA due to oxidation of fatty acids leads to the production of hydroxybutyrate and acetoacetate through ketogenesis. Acetyl-CoA produced by ketone bodies provides acetyl-CoA for the Krebs cycle, which should be provided through $\mathrm{PDC}^{60}$.

Several theories have suggested that $\mathrm{KD}$ reduces seizures ${ }^{104,105}$. Because ATP generation via mitochondria instead of glycolysis selectively activates the potassium channel, it has stabilizing effects on the neuronal cell membrane ${ }^{106,107}$. KD may facilitate this reaction by increasing the production of $\gamma$ aminobutyric acid in the brain tissue. Hence, the hyper-polarization of neurons stabilizes the synaptic function and reduces seizures in the brain.

Acetoacetate, $\beta$-hydroxybutyrate, and acetone are known as ketone bodies that are made from AcetylCoA. Acetyl-CoA is converted to 3-hydroxy-3methylglutaryl-CoA (HMGCoA) by methylglutarylCoA synthase 2 (HMGCS2), the rate-limiting step in ketone body biosynthesis. Eventually, HMGCoA is converted into ketone bodies. Sirt3 and Sirt5 activate the HMGCS2 enzyme and produce ketone bodies through deacetylation and desuccinylation of HMGCS2, respectively ${ }^{108}$. Therefore, Sirt3 and Sirt5 play a role in the treatment of PDC by producing ketone bodies. PDC deficiency inhibits the production of Acetyl-CoA by glucose. Thus, acetyl-CoA of the TCA cycle needs to be achieved through oxidation of fatty acids. Sirt3 produces acetyl-CoA during starvation by deacetylation of the long-chain acyl-CoA dehydrogenase (LCAD), activation of this key enzyme, and beta-oxidation of fatty acids ${ }^{109}$. Sirt3 also produces acetyl-CoA in extracellular tissues through deacetylation and activation of acetyl-CoA synthetase $2^{110,111}$. As a result, Sirt3 can improve the symptoms of PDC through fatty acid catabolism in the liver and the production of acetyl-CoA from acetate in extraliver tissues.

Sirt4 is another critical regulator of fatty acid metabolism and leads to inhibition of oxidation of fatty acids. Sirt4 causes deacetylation of malonyl CoA decarboxylase (MCoAD), thereby activating it. MCoAD plays an important role in the metabolism of fatty acids ${ }^{112}$. Studies on mice have shown that Sirt4 knock-out increases fatty acid oxidation in different tissues $^{31,112}$. Thus Sirt4, in contrast to Sirt3, is a negative regulator of fatty acid oxidation, indicating that Sirt 3 and Sirt 4 are mutually involved in the regulation of lipid metabolism.

Sirt5 is also involved in the regulation of fatty acid metabolism via desuccinylation. It is known that $60 \%$ of the proteins involved in the metabolism of lipids are succinylated. One of the important enzymes involved in the oxidation of fatty acids is hydroxyl coenzyme A dehydrogenase, which is regulated by succinylation and desuccinylation. Sirt5 activates this enzyme via desuccinylation ${ }^{94}$. The overall consequence is that Sirt 3 and Sirt 5 improve the condition of the disease by activating the key enzymes of the ketone body pathway and fatty acid oxidation, resulting in increased production of acetyl-CoA. However, Sirt 4 works the opposite.

\section{OTHER HYPOTHESES RELATED TO THE ROLE OF SIRTUINS IN THE TREATMENT OF PDC DEFICIENCY}

Glucose is converted to pyruvate and lactic acid via the glycolysis pathway. The production of lactic acid increases the PDC deficiency. As a result, reducing glycolysis in PDC is desirable and reduces the amount of lactic acid production. Sirt 3 can reduce the coupling of hexokinase to the voltage-dependent ion channels through cyclophilin D deacetylation, 
and thus the mitochondria membrane ${ }^{113}$. Preventing hexokinase II binding to the mitochondrial membrane reduces glucose-6-phosphate production, and thus, the glycolysis pathway. Pyruvate kinase M1/M2 is another key enzyme of the glycolysis pathway, which is regulated by succinylation. Sirt5 is involved in the glycolysis pathway regulation through the desuccinylation of K498 Lys residue of this enzyme $^{94}$. Consequently, Sirt 3 and Sirt5 are regulated by the glycolysis pathway and can serve as important therapeutic targets.

\section{CONCLUSION AND FUTURE PERSPECTIVES}

$\mathrm{PD}$ is a multi-enzymatic mitochondrial complex that converts pyruvate into acetyl-CoA, CO2, and NADH. This complex consists of three main enzymes (pyruvate dehydrogenase, dihydrolipoamide acetyltransferase, and dihydrolipoamide dehydrogenase) and two regulatory enzymes (PDK and PDP). In general, this complex is regulated in two different ways including end-product inhibition ${ }^{12}$ and posttranslational modifications (phosphorylation and dephosphorylation of subunit E1). Phosphorylation is catalyzed by PDK and dephosphorylation is catalyzed by PDP. The regulation of PDC activity by PDK and PDP results in diverse allosteric modulators such as $\mathrm{NAD}^{+}$, $\mathrm{NADH}, \mathrm{CoASH}$, acetyl-CoA, pyruvate, $\mathrm{ADP}, \mathrm{Ca}^{2+}$, and $\mathrm{Mg}^{2+3,4,6,45-47,49}$. Sirtuins are the class III of histone deacylatases that catalyze protein posttranslational modifications, including deacetylation, ADP ribosylation, and deacylation. Sirt3, Sirt4, and Sirt5 are mitochondrial sirtuins that control PDC by allosteric regulation. Sirt3 enhances the activity of PDC through deacetylation of PDHA1 and PDP1 and inhibition of HIF- $1 \alpha^{84,87}$. Sirt4, which regulates the PDC via lipoamidase, hydrolyzes the lipoamide cofactors in the E2 component of DLAT and decreases PDC activity. Succinylation of PDC increases the complex activity ${ }^{94}$. Sirt5 is another type of mitochondrial sirtuins that causes desuccinylation of Lys residues in proteins ${ }^{96}$. It reduces the activity of this enzyme through desuccinylation of PDC. Consequently, Sirt3 increases the activity of PDC by deacetylation of PDHA1 and PDP1, while Sirt4 and Sirt5 inhibit PDC activity via lipoamidase and desuccinylase activity, respectively.

Mutation in the genes of the PDC enzyme includes a mutation in the PDHA1 gene encoding the alpha subunit of E1, DLAT gene encoding E2 ${ }^{114}$, DLD gene encoding $\mathrm{E} 3^{52}$, and PDHX gene encoding E3binding protein ${ }^{53}$. In the PDC deficiency, the acetylCoA production decreases for the Krebs cycle. In the treatment of PDC deficiency, the use of KD, administration of dichloroacetate and thiamine supplements are recommended to activate PDC and produce acetyl-CoA. Sirt3 enhances the activity of PDC through deacetylation of PDHA1, PDP1, and inhibition of HIF- $1 \alpha$, which appears to be similar to the action of dichloroacetate. Sirt3 can improve the symptoms of PDC by fatty acid catabolism in the liver and the production of acetyl-CoA from acetate in extraliver tissues. Desuccinylation of $\beta$-oxidation enzymes by Sirt5 ${ }^{94}$ increases the production of acetyl-CoA. The overall consequence is that Sirt3 and Sirt5 improve the condition of the disease by activating the key enzyme of the ketone body pathway and fatty acid oxidation, and elevate the production of acetyl-CoA, while Sirt 4 works in the opposite manner. In conclusion, mitochondrial sirtuins are involved in regulating the activity and treatment of PDC deficiency. The compounds can possibly regulate mitochondrial sirtuins, which can be involved in the regulation of PDC. However, extensive studies are required to discover the role of sirtuins in the regulation of PDC.

\section{ABBREVIATIONS}

ACAT1: Acetyl-CoA acetyltransferase 1

ADP: Adenosine diphosphate

ATP: Adenosine triphosphate

CO2: Carbon dioxide

CoA: Coenzyme A

DCA: Dichloroacetate

FAD $^{+}$: flavin adenine dinucleotide

HIF-1 $\alpha$ : Hypoxia inhibitory factor $1-\alpha$

HMGCoA: 3-hydroxy-3-methylglutaryl-CoA

HMGCS2: 3-hydroxy-3-methylglutaryl-CoA synthetase 2

KD: Ketogenic diet

MCoAD: Malonyl CoA decarboxylase

$\mathrm{NAD}^{+}$: Nicotinamide adenine dinucleotide

NADH: Nicotinamide adenine dinucleotide dehydrogenase

PD: Pyruvate dehydrogenase

PDC: Pyruvate dehydrogenase complex

PDH: Pyruvate dehydrogenase E1

PDK: Pyruvate dehydrogenase kinase

PDP: Pyruvate dehydrogenase phosphatase

PTM: Protein posttranslational modifications

Sirt: Sirtuin

\section{COMPETING INTERESTS}

The authors declare that they have no conflicts of interest. 


\section{AUTHORS' CONTRIBUTIONS}

AN and RK contributed to the design of the research. AN and SK extracted the data and summarized it. AV$\mathrm{R}$ and RK edited the first draft. MS and ZA reviewed the first draft. All authors approved the final draft.

\section{ACKNOWLEDGEMENTS}

The financial supports of Kermanshah University of Medical Sciences are gratefully acknowledged (grant number: 97325).

\section{REFERENCES}

1. Behal RH, Buxton DB, Robertson JG, Olson MS. Regulation of the pyruvate dehydrogenase multienzyme complex. Annu Rev Nutr. 1993;13(1):497-520. PMID: 8369156. Available from: 10.1146/annurev.nu.13.070193.002433.

2. Frey PA, Flournoy DS, Gruys K, Yang YS. Intermediates in reductive transacetylation catalyzed by pyruvate dehydrogenase complex. Ann N Y Acad Sci. 1989;573(1):21-35. PMID: 2699398. Available from: 10.1111/j.1749-6632.1989.tb 14984 . $\mathrm{x}$.

3. Patel $M$, Korotchkina L. Regulation of the pyruvate dehydrogenase complex. Portland Press Limited; 2006. Available from: 10.1042/BST0340217.

4. Patel MS, Roche TE. Molecular biology and biochemistry of pyruvate dehydrogenase complexes. FASEB J. 1990;4(14):3224-33. PMID: 2227213. Available from: 10. 1096/fasebj.4.14.2227213.

5. Perham RN, Packman LC. 2-Oxo acid dehydrogenase multienzyme complexes: domains, dynamics, and design. Ann N Y Acad Sci. 1989;573(1):1-20. PMID: 2699393. Available from: 10.1111/j.1749-6632.1989.tb14983.x.

6. Roche TE, Hiromasa Y. Pyruvate dehydrogenase kinase regulatory mechanisms and inhibition in treating diabetes, heart ischemia, and cancer. Cell Mol Life Sci. 2007;64(7-8):830-49. PMID: 17310282. Available from: 10.1007/s00018-007-6380$\mathrm{z}$.

7. Wieland $\mathrm{OH}$. The mammalian pyruvate dehydrogenase complex: structure and regulation. Reviews of Physiology, Biochemistry and Pharmacology. vol. Volume 96. Springer; 1983.

8. Smolle $M$, Prior $A E$, Brown $A E$, Cooper A, Byron O, Lindsay JG. A new level of architectural complexity in the human pyruvate dehydrogenase complex. J Biol Chem. 2006;281(28):19772-80. PMID: 16679318. Available from: 10.1074/jbc.M601140200.

9. Zhou ZH, McCarthy DB, O'Connor CM, Reed LJ, Stoops JK The remarkable structural and functional organization of the eukaryotic pyruvate dehydrogenase complexes. Proc Natl Acad Sci USA. 2001;98(26):14802-7. PMID: 11752427. Available from: 10.1073/pnas.011597698.

10. Maj MC, Cameron JM, Robinson BH. Pyruvate dehydrogenase phosphatase deficiency: orphan disease or an underdiagnosed condition? Mol Cell Endocrinol. 2006;249(1-2):19. PMID: 16574315. Available from: 10.1016/j.mce.2006.02. 003.

11. Yu X, Hiromasa $Y$, Tsen $H$, Stoops JK, Roche TE, Zhou ZH. Structures of the human pyruvate dehydrogenase complex cores: a highly conserved catalytic center with flexible Nterminal domains. Structure. 2008;16(1):104-14. PMID: 18184588. Available from: 10.1016/j.str.2007.10.024.

12. Butterworth RF. Neurotransmitter function in thiaminedeficiency encephalopathy. Neurochem Int. 1982;4(6):449_ 64. PMID: 20487899. Available from: 10.1016/0197-0186(82) 90033-X.

13. Huang B, Gudi R, Wu P, Harris RA, Hamilton J, Popov KM. Isoenzymes of pyruvate dehydrogenase phosphatase. DNAderived amino acid sequences, expression, and regulation. J
Biol Chem. 1998;273(28):17680-8. PMID: 9651365. Available from: $10.1074 / \mathrm{jbc} .273 .28 .17680$.

14. Brown GK, Otero LJ, LeGris M, Brown RM. Pyruvate dehydrogenase deficiency. J Med Genet. 1994;31(11):875-9. PMID: 7853374. Available from: 10.1136/jmg.31.11.875.

15. Meirleir LD. Defects of pyruvate metabolism and the Krebs cycle. J of chil neu. 2002;17(3S):26-33.

16. Hansen LL, Brown GK, Kirby DM, Dahl HH. Characterization of the mutations in three patients with pyruvate dehydrogenase E1 $\alpha$ deficiency. J Inherit Metab Dis. 1991;14(2):140-51. PMID: 1909401. Available from: 10.1007/BF01800586.

17. Imai $S$, Armstrong $C M$, Kaeberlein $M$, Guarente $L$. Transcriptional silencing and longevity protein Sir2 is an NAD-dependent histone deacetylase. Nature. 2000;403(6771):795-800. PMID: 10693811. Available from: $10.1038 / 35001622$.

18. Xu WS, Parmigiani RB, Marks PA. Histone deacetylase inhibitors: molecular mechanisms of action. Oncogene. 2007;26(37):5541-52. PMID: 17694093. Available from: 10.1038/sj.onc. 1210620.

19. Holbert MA, Marmorstein R. Structure and activity of enzymes that remove histone modifications. Curr Opin Struct Biol. 2005;15(6):673-80. PMID: 16263263. Available from: 10.1016/j.sbi.2005.10.006.

20. Sauve AA, Wolberger C, Schramm VL, Boeke JD. The biochemistry of sirtuins. Annu Rev Biochem. 2006;75(1):435-65. PMID: 16756498. Available from: 10.1146/annurev.biochem. 74.082803.133500.

21. Du J, Jiang $\mathrm{H}$, Lin $\mathrm{H}$. Investigating the ADP-ribosyltransferase activity of sirtuins with NAD analogues and 32P-NAD. Biochemistry. 2009;48(13):2878-90. PMID: 19220062. Available from: $10.1021 /$ bi802093g.

22. Michishita E, Park JY, Burneskis JM, Barrett JC, Horikawa I. Evolutionarily conserved and nonconserved cellular localizations and functions of human SIRT proteins. Mol Biol Cell. 2005;16(10):4623-35. PMID: 16079181. Available from: 10.1091/mbc.e05-01-0033.

23. Haigis MC, Guarente LP. Mammalian sirtuins emerging roles in physiology, aging, and calorie restriction. Genes Dev. 2006;20(21):2913-21. PMID: 17079682. Available from: 10.1101/gad.1467506.

24. Ahuja N, Schwer B, Carobbio S, Waltregny D, North BJ, Castronovo V. Regulation of insulin secretion by SIRT4, a mitochondrial ADP-ribosyltransferase. J Biol Chem. 2007;282(46):33583-92. PMID: 17715127. Available from: 10.1074/jbc.M705488200.

25. Yu J, Sadhukhan S, Noriega LG, Moullan N, He B, Weiss RS. Metabolic characterization of a Sirt5 deficient mouse model. Sci Rep. 2013;3(1):2806. PMID: 24076663. Available from: 10.1038/srep02806.

26. Nakagawa T, Lomb DJ, Haigis MC, Guarente L. SIRT5 Deacetylates carbamoyl phosphate synthetase 1 and regulates the urea cycle. Cell. 2009;137(3):560-70. PMID: 19410549. Available from: 10.1016/j.cell.2009.02.026.

27. Kawahara TL, Michishita E, Adler AS, Damian M, Berber $E_{\text {, }}$ Lin M. SIRT6 links histone $\mathrm{H} 3$ lysine 9 deacetylation to NF-kappaB-dependent gene expression and organismal life span. Cell. 2009;136(1):62-74. PMID: 19135889. Available from: 10.1016/j.cell.2008.10.052.

28. Frye RA. Phylogenetic classification of prokaryotic and eukaryotic Sir2-like proteins. Biochem Biophys Res Commun. 2000;273(2):793-8. PMID: 10873683. Available from: 10 . 1006/bbrc. 2000.3000 .

29. Lombard DB, Alt FW, Cheng HL, Bunkenborg J, Streeper RS, Mostoslavsky R. Mammalian Sir2 homolog SIRT3 regulates global mitochondrial lysine acetylation. Mol Cell Biol. 2007;27(24):8807-14. PMID: 17923681. Available from: 10. 1128/MCB.01636-07.

30. Liu L, Nam M, Fan W, Akie TE, Hoaglin DC, Gao G, et al. Nutrient sensing by the mitochondrial transcription machinery dictates oxidative phosphorylation. The $\mathrm{J}$ of clini invest. 
2014;124(2):768. Available from: 10.1172/JCI69413.

31. Nasrin $N$, Wu X, Fortier E, Feng $Y$, Bare' OC, Chen S. SIRT4 regulates fatty acid oxidation and mitochondrial gene expression in liver and muscle cells. J Biol Chem. 2010;285(42):31995-2002. PMID: 20685656. Available from: 10.1074/jbc.M110.124164.

32. Haigis MC, Mostoslavsky R, Haigis KM, Fahie K, Christodoulou DC, Murphy AJ. SIRT4 inhibits glutamate dehydrogenase and opposes the effects of calorie restriction in pancreatic $\beta$ cells. Cell. 2006;126(5):941-54. PMID: 16959573. Available from: 10.1016/j.cell.2006.06.057.

33. German NJ, Haigis MC. Sirtuins and the metabolic hurdles in cancer. Curr Biol. 2015;25(13):569-83. PMID: 26126285. Available from: 10.1016/j.cub.2015.05.012.

34. Sebastián C, Satterstrom FK, Haigis MC, Mostoslavsky R. From sirtuin biology to human diseases: an update. J Biol Chem 2012;287(51):42444-52. PMID: 23086954. Available from: $10.1074 /$ jbc.R112.402768.

35. Margineantu DH, Brown RM, Brown GK, Marcus AH, Capaldi RA. Heterogeneous distribution of pyruvate dehydrogenase in the matrix of mitochondria. Mitochondrion. 2002;1(4):327-38. PMID: 16120287. Available from: 10.1016/ S1567-7249(01)00033-2.

36. Robinson BH, MacKay N, Chun K, Ling M. Disorders of pyruvate carboxylase and the pyruvate dehydrogenase complex. J Inherit Metab Dis. 1996;19(4):452-62. PMID: 8884569. Available from: 10.1007/BF01799106.

37. Arjunan P, Nemeria N, Brunskill A, Chandrasekhar K, Sax M Yan Y. Structure of the pyruvate dehydrogenase multienzyme complex E1 component from Escherichia coli at 1.85 A resolution. Biochemistry. 2002;41(16):5213-21. PMID: 11955070. Available from: 10.1021/bi0118557.

38. Chandrasekhar K, Arjunan P, Sax M, Nemeria N, Jordan F, Furey W. Active-site changes in the pyruvate dehydrogenase multienzyme complex E1 apoenzyme component from Escherichia coli observed at 2.32 A resolution. Acta Crystallogr D Biol Crystallogr. 2006;62(Pt 11):1382-6. PMID: 17057342. Available from: 10.1107/S0907444906034408.

39. Packman LC, Green B, Perham RN. Lipoylation of the E2 components of the 2-oxo acid dehydrogenase multienzyme complexes of Escherichia coli. Biochem J. 1991;277(Pt 1):153-8. PMID: 1854331. Available from: 10.1042/bj2770153.

40. Browning $M$, Baudry $M$, Bennett $W F$, Lynch $G$. Phosphorylation-mediated changes in pyruvate dehydrogenase activity influence pyruvate-supported calcium accumulation by brain mitochondria. J Neurochem. 1981;36(6):1932-40. PMID: 7241145. Available from: 10.1111/j.1471-4159.1981.tb10817.x.

41. Morgan DG, Routtenberg A. Brain pyruvate dehydrogenase: phosphorylation and enzyme activity altered by a training experience. Science. 1981;214(4519):470-1. PMID: 7291989. Available from: 10.1126/science.7291989.

42. Garland PB, Newsholme EA, Randle PJ. Regulation of glucose uptake by muscle. 9 . Effects of fatty acids and ketone bodies, and of alloxan-diabetes and starvation, on pyruvate metabolism and on lactate-pyruvate and L-glycerol 3phosphate-dihydroxyacetone phosphate concentration ratios in rat heart and rat diaphragm muscles. Biochem J. 1964;93(3):665-78. PMID: 4284560. Available from: 10.1042/ bj0930665.

43. Sugden PH, Simister NE. Role of multisite phosphorylation in the regulation of ox kidney pyruvate dehydrogenase complex. FEBS Lett. 1980;111(2):299-302. PMID: 6244187. Available from: 10.1016/0014-5793(80)80814-3.

44. Kerbey AL, Randle PJ. Role of multi-site phosphorylation in regulation of pig heart pyruvate dehydrogenase phosphatase. FEBS Lett. 1979;108(2):485-8. PMID: 230091. Available from: 10.1016/0014-5793(79)80594-3.

45. Baker JC, Yan X, Peng T, Kasten S, Roche TE. Marked differences between two isoforms of human pyruvate dehydrogenase kinase. J Biol Chem. 2000;275(21):15773-81. PMID: 10748134. Available from: 10.1074/jbc.M909488199.
46. Randle PJ. Fuel selection in animals. Portland Press Limited; 1986. Available from: 10.1042/bst0140799.

47. Roche TE, Baker JC, Yan X, Hiromasa Y, Gong X, Peng T. Distinct regulatory properties of pyruvate dehydrogenase kinase and phosphatase isoforms. Prog Nucleic Acid Res Mol Biol. 2001;70:33-75. PMID: 11642366. Available from: 10 . 1016/S0079-6603(01)70013-X.

48. Hansford RG. Studies on the effects of coenzyme A-SH: acetyl coenzyme $A$, nicotinamide adenine dinucleotide: reduced nicotinamide adenine dinucleotide, and adenosine diphosphate: adenosine triphosphate ratios on the interconversion of active and inactive pyruvate dehydrogenase in isolated rat heart mitochondria. J Biol Chem. 1976;251(18):5483-9. PMID: 184082

49. Pratt ML, Roche TE. Mechanism of pyruvate inhibition of kidney pyruvate dehydrogenasea kinase and synergistic inhibition by pyruvate and ADP. J Biol Chem. 1979;254(15):7191-6. PMID: 457675.

50. Kanzaki T, Hayakawa T, Hamada M, Fukuyoshi Y, Koike M Mammalian $\alpha$-keto acid dehydrogenase complexes. IV. Substrate specificities and kinetic properties of the pig heart pyruvate and 2-oxyoglutarate dehydrogenase complexes. J Biol Chem. 1969;244(5):1183-7. PMID: 5812959.

51. Lissens W, Meirleir LD, Seneca S, Liebaers I, Brown GK, Brown RM. Mutations in the X-linked pyruvate dehydrogenase (E1) $\alpha$ subunit gene (PDHA1) in patients with a pyruvate dehydrogenase complex deficiency. Hum Mutat. 2000;15(3):20919. PMID: 10679936. Available from: 10.1002/(SICI)1098 1004(200003)15:3<209::AID-HUMU1>3.0.CO;2-K.

52. Head RA, Brown RM, Zolkipli Z, Shahdadpuri R, King MD, Clayton PT. Clinical and genetic spectrum of pyruvate dehydrogenase deficiency: dihydrolipoamide acetyltransferase (E2) deficiency. Ann Neurol. 2005;58(2):234-41. PMID: 16049940. Available from: 10.1002/ana.20550.

53. Liu TC, Kim H, Arizmendi C, Kitano A, Patel MS. Identification of two missense mutations in a dihydrolipoamide dehydrogenase-deficient patient. Proc Natl Acad Sci USA 1993;90(11):5186-90. PMID: 8506365. Available from: 10. 1073/pnas.90.11.5186.

54. Kerr DS, Wexler ID, Zinn AB. Disorders of pyruvate metabolism and the tricarboxylic acid cycle. Inborn Metabolic Diseases. Springer; 2000.

55. Brown RM, Dahl HH, Brown GK. X-chromosome localization of the functional gene for the E1 $\alpha$ subunit of the human pyruvate dehydrogenase complex. Genomics. 1989;4(2):174-81. PMID: 2737678. Available from: 10.1016/ 0888-7543(89)90297-8.

56. Sperl W, Fleuren $L$, Freisinger $P$, Haack TB, Ribes A, Feichtinger RG. The spectrum of pyruvate oxidation defects in the diagnosis of mitochondrial disorders. J Inherit Metab Dis. 2015;38(3):391-403. PMID: 25526709. Available from: 10.1007/s10545-014-9787-3.

57. Imbard $A$, Boutron $A$, Vequaud $C$, Zater $M$, de Lonlay $P$, de Baulny HO. Molecular characterization of 82 patients with pyruvate dehydrogenase complex deficiency. Structural implications of novel amino acid substitutions in E1 protein. Mol Genet Metab. 2011;104(4):507-16. PMID: 21914562. Available from: 10.1016/j.ymgme.2011.08.008.

58. Quintana E, Gort L, Busquets C, Navarro-Sastre A, Lissens W Moliner S, et al. Mutational study in the PDHA1 gene of 40 patients suspected of pyruvate dehydrogenase complex deficiency. Clin Genet. 2010;77(5):474-82. PMID: 20002461. Available from: 10.1111/j.1399-0004.2009.01313.x.

59. Ridout CK, Keighley P, Krywawych S, Brown RM, Brown GK. A putative exonic splicing enhancer in exon 7 of the PDHA1 gene affects splicing of adjacent exons. Hum Mutat. 2008;29(3):451. PMID: 18273899. Available from: 10.1002/ humu.9525.

60. Saudubray JM, Baumgartner MR, Walter JH. Inborn metabolic diseases: diagnosis and treatment. Springer; 2016. Available from: 10.1007/978-3-662-49771-5. 
61. Meirleir LD, Specola N, Seneca S, Lissens W. Pyruvate dehydrogenase E1 $\alpha$ deficiency in a family: different clinical presentation in two siblings. J Inherit Metab Dis. 1998;21(3):224-6. PMID: 9686362. Available from: 10.1023/ A:1005347501111.

62. Han Z, Zhong L, Srivastava A, Stacpoole PW. Pyruvate dehydrogenase complex deficiency caused by ubiquitination and proteasome-mediated degradation of the E1 subunit. J Biol Chem. 2008;283(1):237-43. PMID: 17923481. Available from: 10.1074/jbc.M704748200.

63. Okajima K, Korotchkina LG, Prasad C, Rupar T, Phillips JA, Ficicioglu C. Mutations of the $\mathrm{E} 1 \beta$ subunit gene (PDHB) in four families with pyruvate dehydrogenase deficiency. Mol Genet Metab. 2008;93(4):371-80. PMID: 18164639. Available from: 10.1016/j.ymgme.2007.10.135.

64. Quintana E, Mayr J, Silva MG, Font A, Tortoledo M, Moliner S. PDH E1 $\beta$ deficiency with novel mutations in two patients with Leigh syndrome. J Inherit Metab Dis. 2009;32(1):33943. Available from: 10.1007/s10545-009-1343-1.

65. Brown RM, Head RA, Brown GK. Pyruvate dehydrogenase E3 binding protein deficiency. Hum Genet. 2002;110(2):187-91. PMID: 11935326. Available from: 10.1007/s00439-001-0665-

66. Brown RM, Head RA, Morris AA, Raiman JA, Walter JH, Whitehouse WP. Pyruvate dehydrogenase E3 binding protein (protein X) deficiency. Dev Med Child Neurol. 2006;48(9):756-60. PMID: 16904023. Available from: 10. 1017/S0012162206001617.

67. Schiff $M$, Miné $M$, Brivet $M$, Marsac $C$, Elmaleh-Bergés $M$, Evrard P. Leigh's disease due to a new mutation in the PDHX gene. Ann Neurol. 2006;59(4):709-14. PMID: 16566017. Available from: 10.1002/ana.20818.

68. Cameron JM, Maj M, Levandovskiy V, Barnett CP, Blaser S, Mackay N. Pyruvate dehydrogenase phosphatase 1 (PDP1) null mutation produces a lethal infantile phenotype. Hum Genet. 2009;125(3):319-26. PMID: 19184109. Available from: 10.1007/s00439-009-0629-6.

69. Kennerson ML, Yiu EM, Chuang DT, Kidambi A, Tso SC, Ly C. A new locus for $\mathrm{X}$-linked dominant Charcot-Marie-Tooth disease (CMTX6) is caused by mutations in the pyruvate dehydrogenase kinase isoenzyme 3 (PDK3) gene. Hum Mol Genet. 2013;22(7):1404-16. PMID: 23297365. Available from: $10.1093 / \mathrm{hmg} / \mathrm{dds} 557$.

70. Barnerias C, Saudubray J, Touati G, Lonlay PD, Dulac O, Ponsot $G$. Pyruvate dehydrogenase complex deficiency: four neurological phenotypes with differing pathogenesis. Develop Medi Chil Neu. 2010;52(2):e1-9. Available from: 10. 1111/j.1469-8749.2009.03541.x.

71. Huq AH, Ito M, Naito E, Saijo T, Takeda E, Kuroda Y. Demonstration of an unstable variant of pyruvate dehydrogenase protein (E1) in cultured fibroblasts from a patient with congenital lactic acidemia. Pediatr Res. 1991;30(1):11-4. PMID: 1909778. Available from: 10.1203/00006450-19910700000003.

72. Onyango $P$, Celic I, McCaffery JM, Boeke JD, Feinberg AP. SIRT3, a human SIR2 homologue, is an NAD-dependent deacetylase localized to mitochondria. Proc Natl Acad Sci USA. 2002;99(21):13653-8. PMID: 12374852. Available from: $10.1073 /$ pnas.222538099.

73. Schwer B, North BJ, Frye RA, Ott M, Verdin E. The human silent information regulator (Sir) 2 homologue hSIRT3 is a mitochondrial nicotinamide adenine dinucleotide-dependent deacetylase. J Cell Biol. 2002;158(4):647-57. PMID: 12186850. Available from: $10.1083 /$ jcb. 200205057.

74. Scher MB, Vaquero A, Reinberg D. SirT3 is a nuclear NAD+dependent histone deacetylase that translocates to the mitochondria upon cellular stress. Genes Dev. 2007;21(8):9208. PMID: 17437997 . Available from: 10.1101/gad.1527307.

75. Palacios OM, Carmona JJ, Michan S, Chen KY, Manabe $Y$, Ward JL. Diet and exercise signals regulate SIRT3 and activate AMPK and PGC- $1 \alpha$ in skeletal muscle. Aging (Albany NY). 2009;1(9):771-83. PMID: 20157566. Available from: 10.18632/aging.100075.

76. Peng $C$, Lu Z, Xie Z, Cheng Z, Chen Y, Tan M, et al. The first identification of lysine malonylation substrates and its regulatory enzyme. Mol Cell Proteomics. 2011;10(12):M111.012658. Available from: 10.1074/mcp.M111.012658.

77. Verdin E, Hirschey MD, Finley LW, Haigis MC. Sirtuin regulation of mitochondria: energy production, apoptosis, and signaling. Trends Biochem Sci. 2010;35(12):669-75. PMID: 20863707. Available from: 10.1016/j.tibs.2010.07.003.

78. Berger SL. The complex language of chromatin regulation during transcription. Nature. 2007;447(7143):407-12. PMID: 17522673. Available from: $10.1038 /$ nature 05915 .

79. Chen $Y$, Sprung $R$, Tang $Y$, Ball $H$, Sangras B, Kim SC. Lysine propionylation and butyrylation are novel posttranslational modifications in histones. Mol Cell Proteomics. 2007;6(5):812-9. PMID: 17267393. Available from: 10.1074/ mcp.M700021-MCP200.

80. Tan M, Luo H, Lee S, Jin F, Yang JS, Montellier E. Identification of 67 histone marks and histone lysine crotonylation as a new type of histone modification. Cell. 2011;146(6):1016-28. PMID: 21925322. Available from: 10.1016/j.cell.2011.08.008.

81. Xie Z, Dai J, Dai L, Tan M, Cheng Z, Wu Y. Lysine succinylation and lysine malonylation in histones. Mol Cell Proteomics. 2012;11(5):100-7. PMID: 22389435. Available from: 10.1074/mcp.M111.015875.

82. Linn TC, Pettit FH, Reed LJ. $\alpha$-keto acid dehydrogenase complexes. X. Regulation of the activity of the pyruvate dehydrogenase complex from beef kidney mitochondria by phosphorylation and dephosphorylation. Proc Natl Acad Sci USA. 1969;62(1):234-41. PMID: 4306045. Available from: 10.1073/ pnas.62.1.234.

83. Holness $M$, Sugden $M$. Regulation of pyruvate dehydrogenase complex activity by reversible phosphorylation. Portland Press Limited; 2003. Available from: 10.1042/ bst0311143.

84. Fan J, Shan C, Kang HB, Elf S, Xie J, Tucker M. Tyr phosphorylation of PDP1 toggles recruitment between ACAT1 and SIRT3 to regulate the pyruvate dehydrogenase complex. Mol Cell. 2014;53(4):534-48. PMID: 24486017. Available from: 10.1016/j.molcel.2013.12.026.

85. Jing E, O'Neill BT, Rardin MJ, Kleinridders A, llkeyeva OR, Ussar S. Sirt3 regulates metabolic flexibility of skeletal muscle through reversible enzymatic deacetylation. Diabetes. 2013;62(10):3404-17. PMID: 23835326. Available from: 10 . 2337/db12-1650.

86. Wieland O, Jagow-Westermann B. ATP-dependent inactivation of heart muscle pyruvate dehydrogenase and reactivation by Mg(++). FEBS Lett. 1969;3(4):271-4. PMID: 11947027. Available from: 10.1016/0014-5793(69)80156-0.

87. Mathias RA, Greco TM, Oberstein A, Budayeva HG, Chakrabarti R, Rowland EA. Sirtuin 4 is a lipoamidase regulating pyruvate dehydrogenase complex activity. Cell. 2014;159(7):1615-25. PMID: 25525879. Available from: 10.1016/j.cell.2014.11.046.

88. Patel KP, O'Brien TW, Subramony SH, Shuster J, Stacpoole PW. The spectrum of pyruvate dehydrogenase complex deficiency: clinical, biochemical and genetic features in 371 patients. Mol Genet Metab. 2012;106(3):385-94. PMID: 22896851. Available from: 10.1016/j.ymgme.2012.03.017.

89. Simpson NE, Han Z, Berendzen KM, Sweeney CA, Oca-Cossio JA, Constantinidis I. Magnetic resonance spectroscopic investigation of mitochondrial fuel metabolism and energetics in cultured human fibroblasts: effects of pyruvate dehydrogenase complex deficiency and dichloroacetate. Mol Genet Metab. 2006;89(1-2):97-105. PMID: 16765624. Available from: 10.1016/j.ymgme.2006.04.015.

90. Finley LW, Carracedo A, Lee J, Souza A, Egia A, Zhang J. SIRT3 opposes reprogramming of cancer cell metabolism through HIF1 $\alpha$ destabilization. Cancer Cell. 2011;19(3):416-28. PMID: 21397863. Available from: 10.1016/j.ccr.2011.02.014. 
91. Muller FL, Liu Y, Remmen HV. Complex III releases superoxide to both sides of the inner mitochondrial membrane. J Bio Chem. 2004;279(47):49064-73. PMID: 15317809. Available from: 10.1074/jbc.M407715200.

92. Rahmatullah M, Radke GA, Andrews PC, Roche TE. Changes in the core of the mammalian-pyruvate dehydrogenase complex upon selective removal of the lipoyl domain from the transacetylase component but not from the protein $X$ component. J Biol Chem. 1990;265(24):14512-7. PMID: 2167319.

93. Zhang Z, Tan M, Xie Z, Dai L, Chen Y, Zhao Y. Identification of lysine succinylation as a new post-translational modification. Nat Chem Biol. 2011;7(1):58-63. PMID: 21151122. Available from: $10.1038 /$ nchembio.495.

94. Park J, Chen Y, Tishkoff DX, Peng C, Tan M, Dai L. SIRT5mediated lysine desuccinylation impacts diverse metabolic pathways. Mol Cell. 2013;50(6):919-30. PMID: 23806337. Available from: 10.1016/j.molcel.2013.06.001.

95. Rardin MJ, He W, Nishida Y, Newman JC, Carrico C, Danielson SR. SIRT5 regulates the mitochondrial lysine succinylome and metabolic networks. Cell Metab. 2013;18(6):920-33. PMID: 24315375. Available from: 10.1016/j.cmet.2013.11.013.

96. Du J, Zhou Y, Su X, Yu JJ, Khan S, Jiang H. Sirt5 is a NAD dependent protein lysine demalonylase and desuccinylase. Science. 2011;334(6057):806-9. PMID: 22076378. Available from: $10.1126 /$ science. 1207861.

97. Parikh S, Cohen BH, Gupta A, Lachhwani DK, Wyllie E, Kotagal P. Metabolic testing in the pediatric epilepsy unit. Pediatr Neurol. 2008;38(3):191-5. PMID: 18279754. Available from: 10.1016/j.pediatrneurol.2007.10.011.

98. Stacpoole PW. Lactic acidosis and other mitochondrial disorders. Metabolism. 1997;46(3):306-21. PMID: 9054475. Available from: 10.1016/S0026-0495(97)90259-6.

99. Maj MC, MacKay N, Levandovskiy V, Addis J, Baumgartner ER, Baumgartner MR. Pyruvate dehydrogenase phosphatase deficiency: identification of the first mutation in two brothers and restoration of activity by protein complementation. Clin Endocrinol Metab. 2005;90(7):4101-7. PMID: 15855260. Available from: 10.1210/jc.2005-0123.

100. Ferriero R, lannuzzi C, Manco G, Brunetti-Pierri N. Differential inhibition of PDKs by phenylbutyrate and enhancement of pyruvate dehydrogenase complex activity by combination with dichloroacetate. J Inherit Metab Dis. 2015;38(5):895904. PMID: 25601413. Available from: 10.1007/s10545-0149808-2.

101. Ferriero R, Boutron A, Brivet M, Kerr D, Morava E, Rodenburg RJ. Phenylbutyrate increases pyruvate dehydrogenase complex activity in cells harboring a variety of defects. Ann Clin Transl Neurol. 2014;1(7):462-70. PMID: 25356417. Available from: 10.1002/acn3.73.

102. Stacpoole PW, Barnes CL, Hurbanis MD, Cannon SL, Kerr DS Treatment of congenital lactic acidosis with dichloroacetate. Arch Dis Child. 1997;77(6):535-41. PMID: 9496194. Available from: $10.1136 /$ adc 77.6 .535

103. Falk RE, Cederbaum SD, Blass JP, Gibson GE, Kark RA, Carrel RE. Ketonic diet in the management of pyruvate dehydrogenase deficiency. Pediatrics. 1976;58(5):713-21. PMID: 824610 .

104. Bough KJ, Rho JM. Anticonvulsant mechanisms of the ketogenic diet. Epilepsia. 2007;48(1):43-58. PMID: 17241207. Available from: 10.1111/j.1528-1167.2007.00915.x.

105. Schwartzkroin PA. Mechanisms underlying the anti-epileptic efficacy of the ketogenic diet. Epilepsy Res. 1999;37(3):17180. PMID: 10584967. Available from: 10.1016/S0920-1211(99) 00069-8.

106. Danial NN, Hartman AL, Stafstrom CE, Thio LL. How does the ketogenic diet work? Four potential mechanisms. J of chil neu. 2013;28(8):1027-33. PMID: PMC3971996. Available from: $10.1177 / 0883073813487598$.

107. Neal E. Dietary treatment of epilepsy: practical implementation of ketogenic therapy. John Wiley \& Sons; 2012. Available from: 10.1002/9781118702772.

108. Shimazu T, Hirschey MD, Hua L, Dittenhafer-Reed KE, Schwer B, Lombard DB, et al. SIRT3 deacetylates mitochondrial 3hydroxy-3-methylglutaryl CoA synthase 2 and regulates ketone body production. Cell Metab. 2010;12(6):654-61. PMID 21109197. Available from: 10.1016/j.cmet.2010.11.003.

109. Hirschey MD, Shimazu T, Goetzman E, Jing E, Schwer B, Lombard DB. SIRT3 regulates mitochondrial fatty-acid oxidation by reversible enzyme deacetylation. Nature. 2010;464(7285):121-5. PMID: 20203611. Available from: 10.1038 /nature 08778 .

110. Schwer B, Bunkenborg J, Verdin RO, Andersen JS, Verdin E. Reversible lysine acetylation controls the activity of the mitochondrial enzyme acetyl-CoA synthetase 2. Proc Natl Acad Sci USA. 2006;103(27):10224-9. PMID: 16788062. Available from: 10.1073/pnas.0603968103.

111. Hallows WC, Lee S, Denu JM. Sirtuins deacetylate and activate mammalian acetyl-CoA synthetases. Proc Natl Acad Sci USA. 2006;103(27):10230-5. PMID: 16790548. Available from: 10.1073/pnas.0604392103.

112. Laurent G, German NJ, Saha AK, de Boer VC, Davies M, Koves TR. SIRT4 coordinates the balance between lipid synthesis and catabolism by repressing malonyl CoA decarboxylase. Mol Cell. 2013;50(5):686-98. PMID: 23746352. Available from: 10.1016/j.molcel.2013.05.012.

113. Shulga N, Pastorino JG. Ethanol sensitizes mitochondria to the permeability transition by inhibiting deacetylation of cyclophilin-D mediated by sirtuin-3. J Cell Sci. 2010;123(Pt 23):4117-27. PMID: 21062897. Available from: $10.1242 / \mathrm{jcs}$. 073502.

114. Brown RM, Head RA, Boubriak II, Leonard JV, Thomas NH, Brown GK. Mutations in the gene for the E1 $\beta$ subunit: a novel cause of pyruvate dehydrogenase deficiency. Hum Genet. 2004;115(2):123-7. PMID: 15138885. Available from: 10.1007/s00439-004-1124-8. 